\title{
Posterior Temporary Fixation of C1-2 Screw-rod System for Unstable C1 Burst Fracture
}

\author{
Yun-lin Chen \\ Ningbo No.6 Hospital \\ Xu-dong $\mathrm{Hu}$ \\ Ningbo No.6 Hospital \\ Yang Wang \\ Ningbo No.6 Hospital \\ Wei-yu Jiang ( $\square$ charleschen1991@163.com ) \\ Ningbo No.6 Hospital \\ Wei-hu Ma \\ Ningbo No.6 Hospital
}

\section{Research article}

Keywords: posterior C1-C2 temporary fixation, C1 burst fracture, rotational function

Posted Date: December 10th, 2020

DOl: https://doi.org/10.21203/rs.3.rs-122622/v1

License: (c) (1) This work is licensed under a Creative Commons Attribution 4.0 International License. Read Full License 


\section{Abstract}

Background Whether an unstable $\mathrm{C} 1$ burst fracture should be treated surgically or conservatively is controversial. The purpose of this study is to evaluate the effectiveness and motion-preserving function of temporary fixation of $\mathrm{C} 1-2$ screw-rod system for the reduction and fixation of unstable $\mathrm{C} 1$ burst fracture (type 3 and 4 according to the Gehweiler classification).

Patients and Methods We retrospectively reviewed 10 patients who were treated with posterior temporary C1-C2 fixation. We assessed age at surgery, gender, pre- and post-operative VAS, NDI, atlanto-dens interval, lateral mass distance and rotation function of C1-C2 complex.

Results 6 males and 4 females were included in our study. The average follow-up duration was $14.1 \pm$ 1.37 months. The left-to-right ROMs of $\mathrm{C} 1-\mathrm{C} 2$ rotation was $9.6 \pm 1.42^{\circ}$. The pre-operative cervical VAS was $8.30 \pm 0.48$; the post-operative cervical VAS of $\mathrm{C} 1-\mathrm{C} 2$ fusion was $2.90 \pm 0.57$. The pre-operative VAS for removal was $2.0 \pm 0.00$, the post-operative VAS for removal was $2.3 \pm 0.48$; The pre-operative cervical NDI was $81.40 \% \pm 2.07 \%$, the post-operative cervical NDI of C1-C2 fusion was $18.10 \% \pm 1.52 \%$. The preoperative NDI for removal was $15.9 \% \pm 1.20 \%$, The post-operative NDI for removal was $14.5 \% \pm 1.08 \%$. The preoperative ADI was $4.43 \pm 0.34 \mathrm{~mm}$, post-operative ADI was $1.94 \pm 0.72 \mathrm{~mm}$. The pre-operative LMD was $6.36 \pm 0.58 \mathrm{~mm}$, post-operative LMD was $1.64 \pm 0.31 \mathrm{~mm}$.

Conclusion Posterior temporary C1-2 fixation can achieve a good fusion, satisfied reduction of C1 burst fracture, relieve the pain, improve the cervical function outcome, but may reduce the rotational ROM of C1-2. Temporary C1- $\mathrm{C} 2$ fixation is an alternative technique to manage the $\mathrm{C} 1$ burst fracture, but the need for implant removal needs to be questioned. For patients with CT scan before implant removal showing spontaneous fusion, they may potentially not profit from implant removal.

\section{Introduction}

The first cervical vertebra, also known as the atlas, is a crucial part of the craniocervcal junction and the upper cervical spine. The atlas is a simple ring with 2 lateral masses bridged by anterior and posterior arches. It acts as a transitional structure between $\mathrm{C} 0$ and $\mathrm{C} 2$. Atlas fractures is the second most common injury of the upper cervical spine, they have accounted for $25 \%$ of the craniocervical injuries, $2 \%-13 \%$ of all cervical spine injuries and around $1 \%-3 \%$ of all spine fractures ${ }^{[1]}$. The most common cause is axial loading on the osseous ring of the atlas such as the motor vehicle accidents and fall ${ }^{[1]}$.

Isolated fracture of type 1,2 and 5 were preferably managed conservatively according to the Gehweiler classification ${ }^{2]}$. Whether an unstable $\mathrm{C} 1$ burst fracture (type 3 and 4) should be treated surgically or conservatively is controversial ${ }^{[3]}$. Previously, most of the patients with stable atlas fracture were treated with external immobilization. However, the outcome is not satisfied. Lewkonia et al ${ }^{[4]}$ performed a literature review about the outcome of conservative treatment of $\mathrm{C} 1$ burst fractures. They described a rate of $8-20 \%$ with complaints about stiffness in the neck, a rate of $14 \%-80 \%$ with mild pain and a rate of 
$34 \%$ of patients with limitations of their activities. Moreover, apparent malunions and nonunions after conservation have been reported ${ }^{[5]}$.

Hence, there are some studies describing the outcome of operative treatment of unstable atlas fractures. Surgical treatments of $\mathrm{C} 1$ fracture include direct open-reduction internal fixation (ORIF) of the $\mathrm{C} 1, \mathrm{C} 1-\mathrm{C} 2$ fusion. Ma et al ${ }^{[6]}$ treated 20 patients with transpolar screws combined with plate, all patients had bony fusion without any instability and complications in 6 months follow-up. Sun et al ${ }^{[7]}$ treated 8 patients with the same method; all patients had bony fusion without operative complications in 6-24 months follow-up. He et al ${ }^{[8]}$ treated 22 patients with posterior polyaxial screws and plate, a good bony fusion and normal physiological range of motion were described in all 22 patients. ORIF of the $\mathrm{C} 1$ can preserve the motion function of $\mathrm{C} 1-\mathrm{C} 2$ rotation ${ }^{[6]}$, but some studies also showed it may accelerate cervical spondylosis in remaining segments ${ }^{[9-10]}$. Also, the transoral approach has the risk of wound complications ${ }^{[11]}$. The ORIF of $\mathrm{C} 1$ needs more studies to ensure the clinical effects. Atlantoaxial (C1-C2) fusion represents the standard treatment for the $C 1$ burst fracture or $C 1-C 2$ subluxation ${ }^{[3,12,13]}$. However the fusion may result to the loss of $50 \%$ cervical rotation, which limited the $\mathrm{C} 1-\mathrm{C} 2$ arthrodesis as a primary treatment.

Posterior temporary C1-C2 fixation can preserve the motion of the C1-2 complex. Some studies described this method using for type III odontoid fractures, showed good clinical outcomes ${ }^{[14,15]}$. This is the first study of $\mathrm{C} 1$ burst fracture stabilized by a motion-preserving method with a posterior temporary C1-C2 fixation. The purpose of this study is to evaluate the effectiveness and motion-preserving function of temporary $\mathrm{C} 1-\mathrm{C} 2$ screw-rod system for the reduction and fixation of unstable $\mathrm{C} 1$ burst fracture.

\section{Materials And Methods}

The ethical committee of our hospital approved this study. Informed consent is given or provided by all patients. All patients were performed in accordance with relevant guidelines and regulations. Informed consent for publication for identifying images was obtained from all patients. We retrospectively reviewed the date for 10 patients who underwent posterior $\mathrm{C} 1-2$ temporary fixation because of $\mathrm{C} 1$ burst fracture from January 2015 to June 2018. The inclusion criteria included (1) patients with $\mathrm{C} 1$ burst fracture who could not tolerate long-term external fixation (type 3 and 4 according to the Gehweiler classification); (2) patients whose fracture reduction could not achieved with conservative treatment; (3) patients refused to undergo the anterior approach. The exclusion criteria were (1) patients without intact transverse ligament; (2) the condition of patients could not tolerate the operation; (3) patients > 65 years of age. All fractures were confirmed with plain cervical spine radiograph, computed tomography (CT), and magnetic resonance imaging (MRI). Skull traction was performed routinely after admission to stabilize the fracture with $2-\mathrm{kg}$ weight.

Under general anesthesia, a 6-8 $\mathrm{cm}$ posterior midline incision is made to exposure the posterior structure of the upper cervical spine. C1 lateral mass screws combined with $\mathrm{C} 2$ pedicle screws without 
fusion(Shanghai Sanyou Company, China)were performed for each patient.

Anterior-posterior, lateral, mouth-open and dynamic radiographs were taken preoperatively and 3 , 6 months and 1 year postoperatively. CT scans was obtained since 3 months postoperatively. Fracture healing was defined as evident bridging bone across the $\mathrm{C} 1$ fracture on $\mathrm{CT}$ construction. Time to fracture healing was recorded. After fracture healing, the implants were removed to preserve the C1-2 complex motion. All patients wore a Philadelphia collar postoperatively for 4 weeks postoperatively.

The data collected for analysis included operation time, clinical and radiographic results and complications. Patients were followed in outpatient clinic after initial treatment. Visual analog scale score for neck pain ${ }^{[16]}$, Neck Disability Index (NDI) ${ }^{[17]}$ for four groups (pre-operative and post-operative of C1C2 fusion, pre-operative and post-operative of removal of C1-2 screw-rod system) were evaluated as functional outcomes. The preoperative and postoperative atlanto-dens interval (ADI) and lateral mass distance (LMD) were recorded to evaluation the reduction of fracture. The rotational capacity of the C1-2 complex was measure by functional CT scans obtained in the supine position after 1 month of the removal. All patients underwent functional CT scans with the head first fully rotated to one side and then to the opposite side to evaluate the range of motion of C1-2 complex. C1-C2 ROM in rotation was the sum of the values from the $\mathrm{C} 1$ angles subtraction the $\mathrm{C} 2$ angles at the each side (Fig. 1).

The data were analyzed using SPSS Statistics for Mac, Version 22 (SPSS Inc., Chicago, IL, USA). Statistics significance was defined as $p<0.05$.

\section{Results}

Four women and six men with an average age of 39.6 years (range, 32-47) were included in our study. There are eight patients diagnosed with Type 3 and two with Type 4 according to the Gehweiler classification. All patients achieved fracture healing, the average fusion time was $5.10 \pm 0.88$ months (range: 4-6 months). After the fusion of fracture, we removed the internal fixation system. The average follow-up duration was $14.1 \pm 1.37$ months (range: 12-16 months). 3 patients were injured by motor vehicle accident, while others were by falling. All patients had no neurological deficit (ASIA: grade E.), there were no complications for all patients (Table 1). 
Table 1

Details of included patients.

\begin{tabular}{|c|c|c|c|c|c|c|}
\hline $\begin{array}{l}\text { Age } \\
\text { (years) }\end{array}$ & Gender & $\begin{array}{l}\text { Reasons } \\
\text { of injury }\end{array}$ & $\begin{array}{l}\text { ASIA } \\
\text { grade }\end{array}$ & $\begin{array}{l}\text { Follow- } \\
\text { up } \\
\text { (months) }\end{array}$ & $\begin{array}{l}\text { Removal time } \\
\text { (months) (post-op C1- } \\
2 \text { fusion) }\end{array}$ & $\begin{array}{l}\text { Fracture } \\
\text { Classification } \\
\text { (Gehweiler type) }\end{array}$ \\
\hline 32 & $M$ & $\begin{array}{l}\text { Motor } \\
\text { vehicle } \\
\text { accident }\end{array}$ & $E$ & 15 & 4 & 4 \\
\hline 47 & $\mathrm{~F}$ & Fall & $E$ & 16 & 5 & 4 \\
\hline 40 & $M$ & Fall & $E$ & 14 & 6 & 4 \\
\hline 38 & $M$ & $\begin{array}{l}\text { Motor } \\
\text { vehicle } \\
\text { accident }\end{array}$ & $E$ & 12 & 6 & 4 \\
\hline 42 & $M$ & $\begin{array}{l}\text { Motor } \\
\text { vehicle } \\
\text { accident }\end{array}$ & $\mathrm{E}$ & 13 & 5 & 3 \\
\hline 45 & $\mathrm{~F}$ & Fall & $E$ & 14 & 6 & 3 \\
\hline 36 & $\mathrm{~F}$ & Fall & $E$ & 13 & 4 & 4 \\
\hline 38 & $M$ & Fall & $E$ & 13 & 4 & 4 \\
\hline 40 & $M$ & Fall & $E$ & 15 & 6 & 4 \\
\hline 38 & $\mathrm{~F}$ & Fall & $E$ & 16 & 5 & 4 \\
\hline
\end{tabular}

The pre-operative cervical VAS was $8.30 \pm 0.48$; the post-operative cervical VAS of C1-C2 fusion was 2.90 \pm 0.57 , which was significant less than pre-operative group $(p<0.05)$. The pre-operative VAS for removal was $2.0 \pm 0.00$, which was significant less than post-operative fixation group. The post-operative VAS for removal was $2.3 \pm 0.48$; there was no significant difference with pre-operative removal group $(p=0.08)$. The pre-operative cervical NDI was $81.40 \% \pm 2.07 \%$, the post-operative cervical NDI of C1-C2 fusion was $18.10 \% \pm 1.52 \%$, which was significant less than pre-operative group $(p<0.05)$. The preoperative NDI for removal was $15.9 \% \pm 1.20 \%$, which was significant less than post-operative fixation group $(p<0.05)$. The post-operative NDI for removal was $14.5 \% \pm 1.08 \%$, which was significant less than pre-operative removal group $(\mathrm{p}<0.05)$.

The pre-operative ADI was $4.43 \pm 0.34 \mathrm{~mm}$, post-operative ADI was $1.94 \pm 0.72 \mathrm{~mm}$, there was significant difference between two groups $(p<0.05)$. The pre-operative LMD was $6.36 \pm 0.58 \mathrm{~mm}$, post-operative LMD was $1.64 \pm 0.31 \mathrm{~mm}$, there was significant difference between two groups $(p<0.05)$.

The left-to-right ROM of C1-C2 rotation was $9.6 \pm 1.42^{\circ}$. The range of ROM was significant decreased when compared to the Roche' study (right: $32.4 \pm 8.2$; left: $34.2 \pm 9.4)(p<0.05)^{[18]}$. 


\section{Discussion}

Our study showed posterior temporary fixation of $\mathrm{C} 1$ burst fracture can achieve a good fusion and satisfied reduction of $\mathrm{C} 1$ fracture, relieve the pain, improve the cervical function outcome, but may reduce the rotational ROM of $\mathrm{C} 1-2$.

Whether an unstable $\mathrm{C} 1$ burst fracture (type 3 and 4 according to the Gehweiler's classification) should be treated surgically or conservatively is controversial. Isolated $\mathrm{C} 1$ fracture was often conservatively managed. Kesterson reported 17 patients diagnosed with Jefferson fracture. In 13 cases of isolated C1 burst fractures were treated with external immobilization successfully ${ }^{[19]}$. However, Kandziora reported malunion and nonunion with atlas fractures who were treated with external immobilization ${ }^{[5]}$. So, some studies favor surgery for $\mathrm{C} 1$ burst fracture, particularly in the presence of transverse ligament disruption. If instability was identified after external immobilization, a C0-C2 fusion or $\mathrm{C} 1-\mathrm{C} 2$ fusion should be performed to prevent neurological deficit $[20,21]$.

Several studies showed posterior C1-2 temporary fixation (PTF) could preserve the rotation motion of the C1-2 complex. Guo et al. showed the outcomes of PTF and external immobilization were comparable for treating type III odontoid fractures ${ }^{[14]}$. Han et al. showed C1-2 segment fixation without anterior screw might reduce the rotation function of C1-2 complex (27.3\%) when treated for type II dens fracture ${ }^{[22]}$. In our study, posterior C1-2 temporary fixation can achieve a good fusion of $\mathrm{C} 1$ fracture, however it also reduces the rotation function of $\mathrm{C} 1-2$ complex.

Fracture healing restores the tissue to its original physical and mechanical properties and is influenced by a variety of systematic and local factors ${ }^{[23]}$. Healing process can be classified into three stages: the early inflammatory stage; the repair stage; and the late remodeling. In the first inflammatory stage, a hematoma develops within the fracture site during the first few hours and days. Inflammatory cells and fibroblasts infiltrate the bone, resulting in the formation of granulation tissue. We found C1-C2 fusion occurred between posterior border of the anterior arch and apex of C2 (Red arrow in Fig. 2). We assumed the hematoma and inflammatory cells during the first inflammatory stage caused by the $\mathrm{C} 1$ fracture might result to the fusion of $\mathrm{C} 1-2$ complex. Because the fracture location of $\mathrm{C} 1$ burst fracture and apex of $\mathrm{C} 2$ was at the same level, the C1-C2 fixation limited the motion of C1-C2 complex, while; the location of type III odontoid fracture was at different levels when compared to $\mathrm{C} 1$.

Temporary $\mathrm{C} 1-\mathrm{C} 2$ fixation is an alternative technique to manage the $\mathrm{C} 1$ burst fracture, but the need for implant removal needs to be questioned. For patients with CT scan before implant removal showing spontaneous fusion, they may potentially not profit from implant removal.

There are several limitations of our study. Firstly, this is a retrospective study. Secondly, the small number of patients has potential bias. In addition, our study lacks of the control group. The further prospective study with more patients is necessary. 


\section{Conclusion}

In conclusion, posterior temporary C1-2 fixation can achieve a good fusion and satisfied reduction of C1 fracture, relieve the pain, improve the cervical function outcome, but may reduce the rotational ROM of C1-2. Temporary $\mathrm{C} 1-\mathrm{C} 2$ fixation is an alternative technique to manage the $\mathrm{C} 1$ burst fracture, but the need for implant removal needs to be questioned. For patients with CT scan before implant removal showing spontaneous fusion, they may potentially not profit from implant removal.

\section{Declarations}

\section{Conflict of interest}

The authors declare that they have no competing interests.

\section{Funding}

The Program of Natural Science Foundation of Zhejiang Province (LY18H060007) funded this study.

\section{Author contributions}

All authors participated in the management of the patient. CYL drafted the manuscript. CYL and WY collected the clinical data; JWY and HXD wrote discussion and introduction. JWY and MWH supervised the case and also supervised the writing of the manuscript. All authors read and approved the manuscript.

\section{Ethics approval and consent to participate}

The patient and her family have provided consent to participate.

\section{Consent for publication}

The patient and her family have provided consent for the data in this case report to be published.

\section{Acknowledgements}

Not Applicable.

\section{Available of data and materials}

The datasets used and analysed during the current study are available from the corresponding author on reasonable request.

\section{References}

1. Kakarla UK. et al. Atlas fractures. Neurosurgery.66:60-67 (2010). 
2. Gehweiler JA, Osborne RL, Becker RF. The Radiology of Vertebral Trauma. New York: W.B Saunders Company (1980).

3. Kandziora F. et al. Treatment of Atlas Fractures: Recommendations of the Spine Section of the German Society for Orthopaedics and Trauma (DGOU)[J]. Global Spine Journal, 8(2_suppl):5S-11S (2018).

4. Lewkonia P. et al. An evidence-based medicine process to determine outcomes after cervical spine trauma. Spine. 37:E1140-E1147 (2012).

5. Kandziora Frank. et al. Atlas Fractures and Atlas Osteosynthesis: A Comprehensive Narrative Review. J Orthop Trauma, S81-S89 (2017).

6. Ma W. et al. Unstable atlas fracture treatment by anterior plate C1-ring osteosynthesis using a transoral approach. Eur Spine J. 22:2232-2239 (2013).

7. Sun SH. et al. Transoral plate internal fixation for treatment of instability atlas fracture. Zhongguo Gu Shang. 26:81-84 (2013).

8. He B. et al. Self-designed posterior atlas polyaxial lateral mass screwplate fixation for unstable atlas fracture. Spine J. 14: 2892-2896 (2014).

9. Shin Jun Jae. et al. Comparison of Adjacent Segment Degeneration, Cervical Alignment, and Clinical Outcomes After One- and Multilevel Anterior Cervical Discectomy and Fusion.[J] .Neurospine, 16: 589-600 (2019).

10. Lee JC. et al. Risk-factor analysis of adjacent- segment pathology requiring surgery following anterior, posterior, fusion, and nonfusion cervical spine operations. J Bone Joint Surg Am;96:17611767 (2014).

11. Zou Xiaobao. et al. [Progress in treatment of unstable atlas fracture].[J] .Zhongguo Xiu Fu Chong Jian Wai Ke Za Zhi, 34: 793-796 (2020).

12. Goel A, Laheri V. Plate and screw fixation for atlanto-axial subluxation. Acta Neurochir (Wien);129:47-53 (1994).

13. Harms J, Melcher RP. Posterior C1-C2 fusion with polyaxial screw and rod fixation. Spine (Phila Pa 1976). Nov 15;26(22):2467-71 (2001).

14. Guo Q. et al. Posterior Temporary Fixation Versus Nonoperative Treatment for Anderson-D'Alonzo Type $\otimes$ Odontoid Fractures: Functional CT Evaluation of C1- C2 Rotation. World Neurosurgery, 100 (2016).

15. Ni B. et al. Posterior reduction and temporary fixation for odontoid fracture: a salvage maneuver to anterior screw fixation. Spine (Phila Pa 1976). Feb 1;40(3):E168-74 (2015).

16. Huskisson EC. Measurement of pain. Lancet. 2(7889):1127-1131 (1974).

17. Sterling M, Rebbeck T. The Neck Disability Index (NDI). Aust J Physiother. 51(4):271 (2005).

18. Roche C J. et al. The Atlanto-axial Joint: Physiological Range of Rotation on MRI and CT[J]. Clinical Radiology, 57(2):0-108 (2002). 
19. Kesterson L. et al. Evaluation and treatment of atlas burst fractures (Jefferson fractures). $J$ Neurosurg. 75(2):213-220 (1991).

20. Lleu Maxime. et al. $\mathrm{C} 1$ fracture: Analysis of consolidation and complications rates in a prospective multicenter series.[J] .Orthop Traumatol Surg Res, 104: 1049-1054 (2018).

21. Tessitore E, Momjian A, Payer M. Posterior reduction and fixation of an unstable Jefferson fracture with $\mathrm{C} 1$ lateral mass screws, $\mathrm{C} 2$ isthmus screws, and crosslink fixation: technical case report. Neurosurgery. 63(1 Suppl 1) (2008).

22. Han Bin, Chen Qixin, Li Fangcai. C1-2 segmental fixation without anterior screw for the motionpreservative treatment of type II dens injuries [J]. Chin J Orthop, 35(5): 542-550 (2015).

23. Shiu Hoi Ting, Leung Ping Chung, Ko Chun Hay, The roles of cellular and molecular components of a hematoma at early stage of bone healing.[J]. J Tissue Eng Regen Med, 12: e1911-e1925 (2018).

\section{Figures}




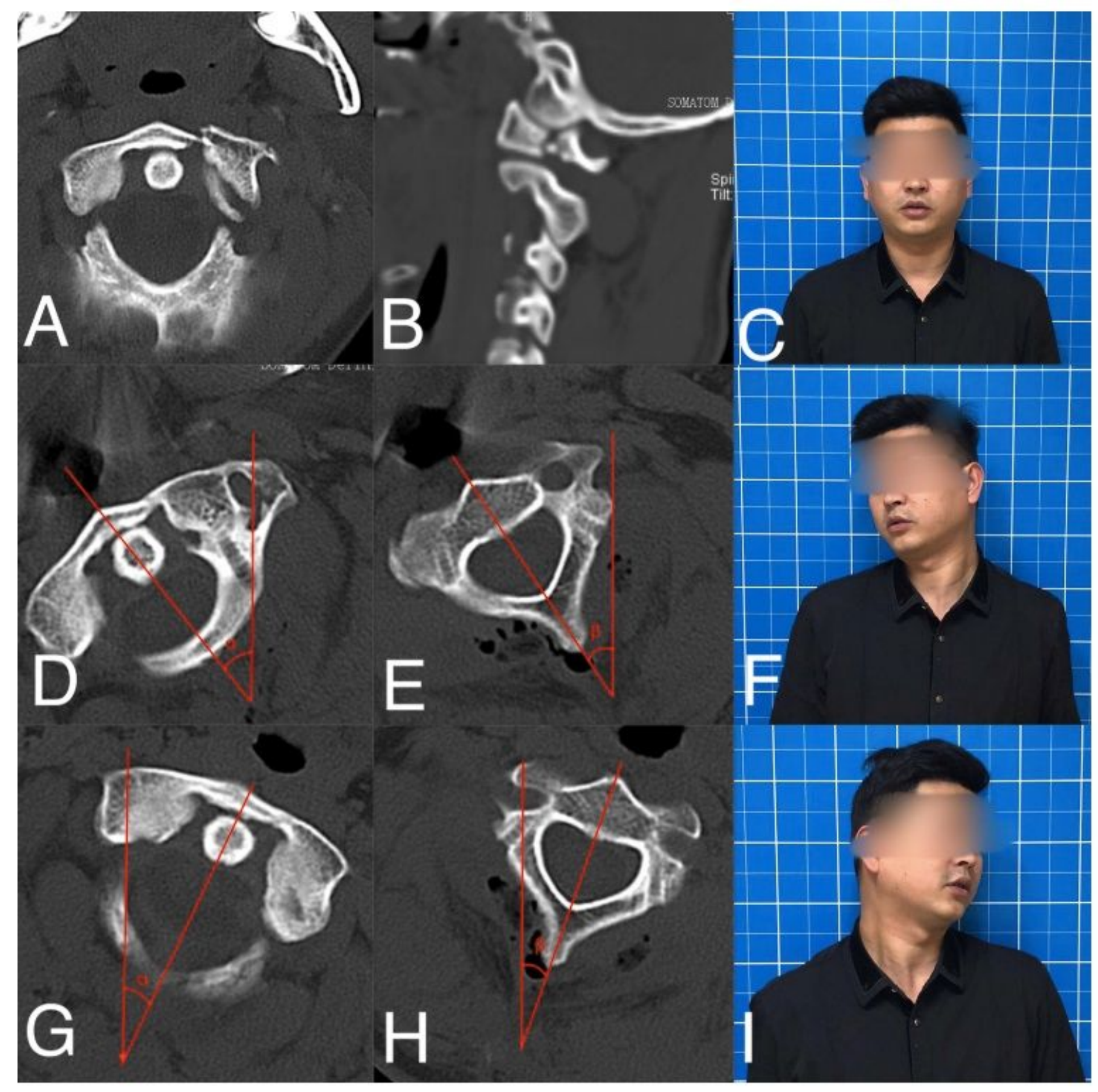

\section{Figure 1}

$A$ (axial view) and B (sagittal view) showed $C 1$ burst fracture. $C$ showed the neutral position of the patient. $\mathrm{D}$ showed maximum angle of $\mathrm{C} 1$ on the right side; $\mathrm{E}$ showed maximum angle of $\mathrm{C} 2$ on the right side; $\mathrm{G}$ showed maximum angle of $\mathrm{C} 1$ on the left side; $\mathrm{H}$ showed maximum angle of $\mathrm{C} 2$ on the left side; $\mathrm{a}$ $\beta$ means the rotation angle of $\mathrm{C} 1-2$ complex on each side. 


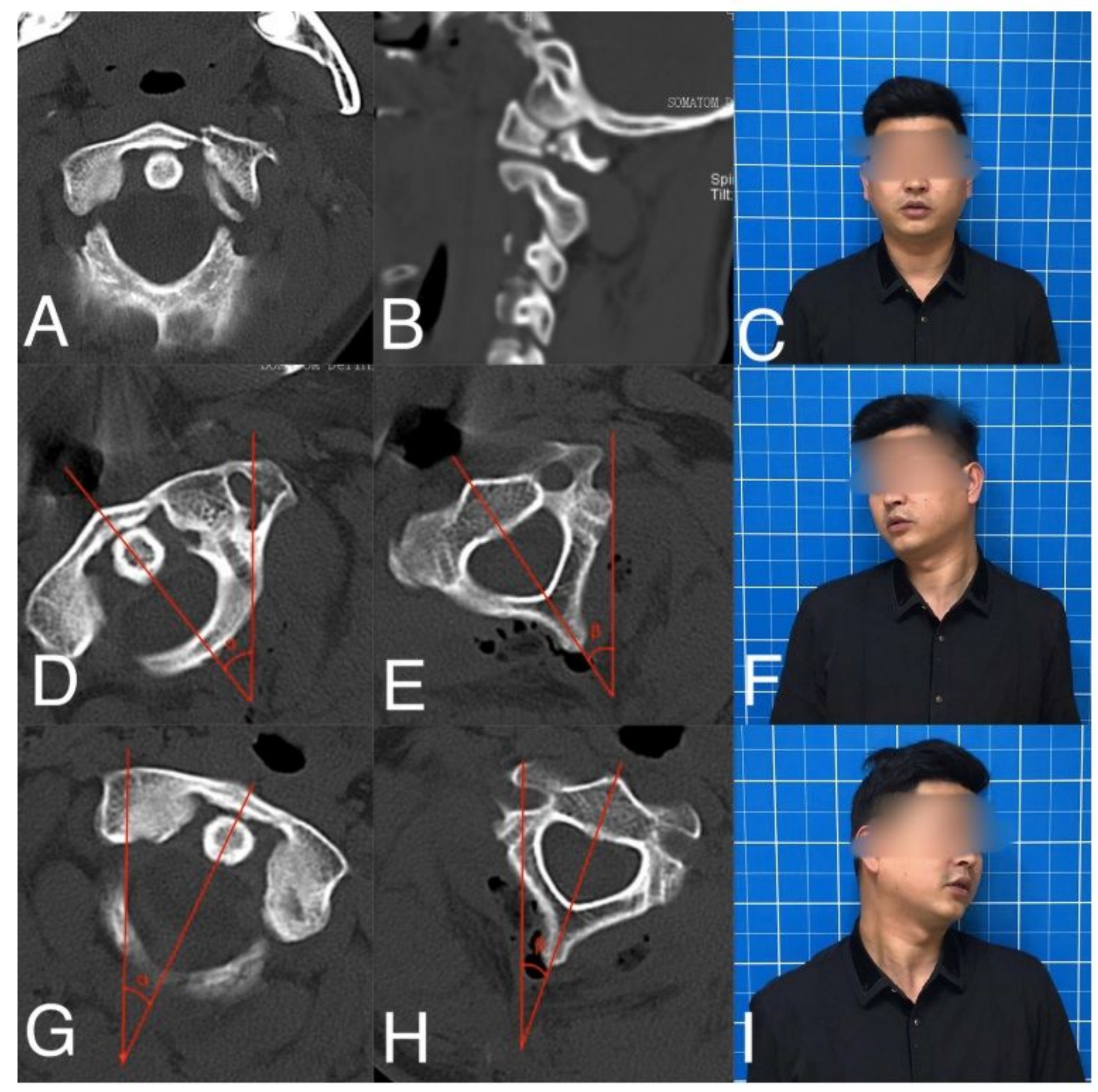

\section{Figure 1}

$A$ (axial view) and B (sagittal view) showed $C 1$ burst fracture. $C$ showed the neutral position of the patient. $\mathrm{D}$ showed maximum angle of $\mathrm{C} 1$ on the right side; $\mathrm{E}$ showed maximum angle of $\mathrm{C} 2$ on the right side; $\mathrm{G}$ showed maximum angle of $\mathrm{C} 1$ on the left side; $\mathrm{H}$ showed maximum angle of $\mathrm{C} 2$ on the left side; $\mathrm{a}$ $\beta$ means the rotation angle of $\mathrm{C} 1-2$ complex on each side. 


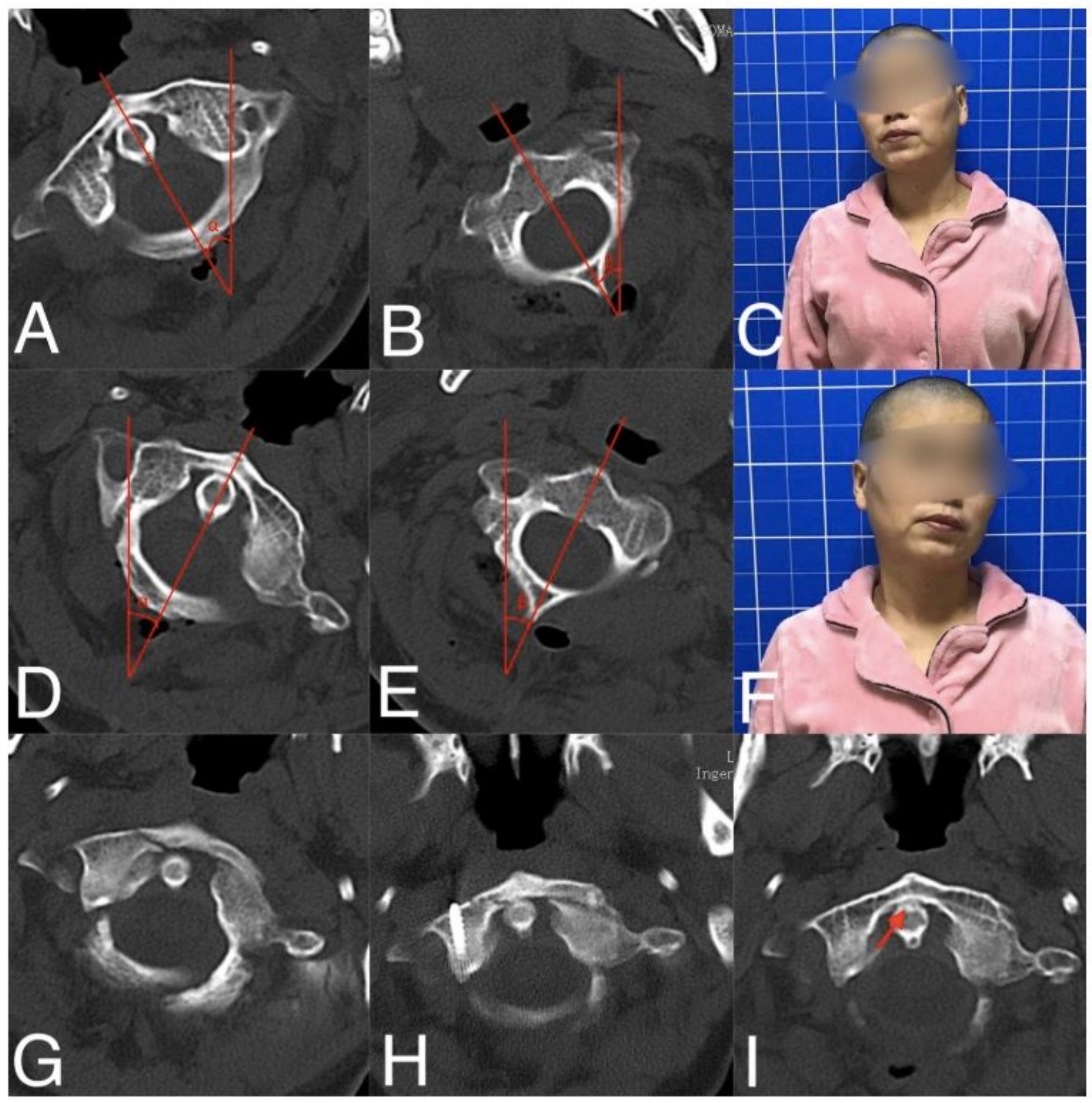

Figure 2

A showed maximum angle of $\mathrm{C} 1$ on the right side; $\mathrm{B}$ showed maximum angle of $\mathrm{C} 2$ on the right side. $\mathrm{D}$ showed maximum angle of $\mathrm{C} 1$ on the left side; $\mathrm{E}$ showed maximum angle of $\mathrm{C} 2$ on the left side. $\mathrm{G}$ showed $\mathrm{C} 1$ burst fracture before the operation. $\mathrm{H}$ showed post-operative of $\mathrm{C} 1$ after 3 months. I showed the union of posterior border of $\mathrm{C} 1$ anterior arch and apex of $\mathrm{C} 2$ (Red arrow). 


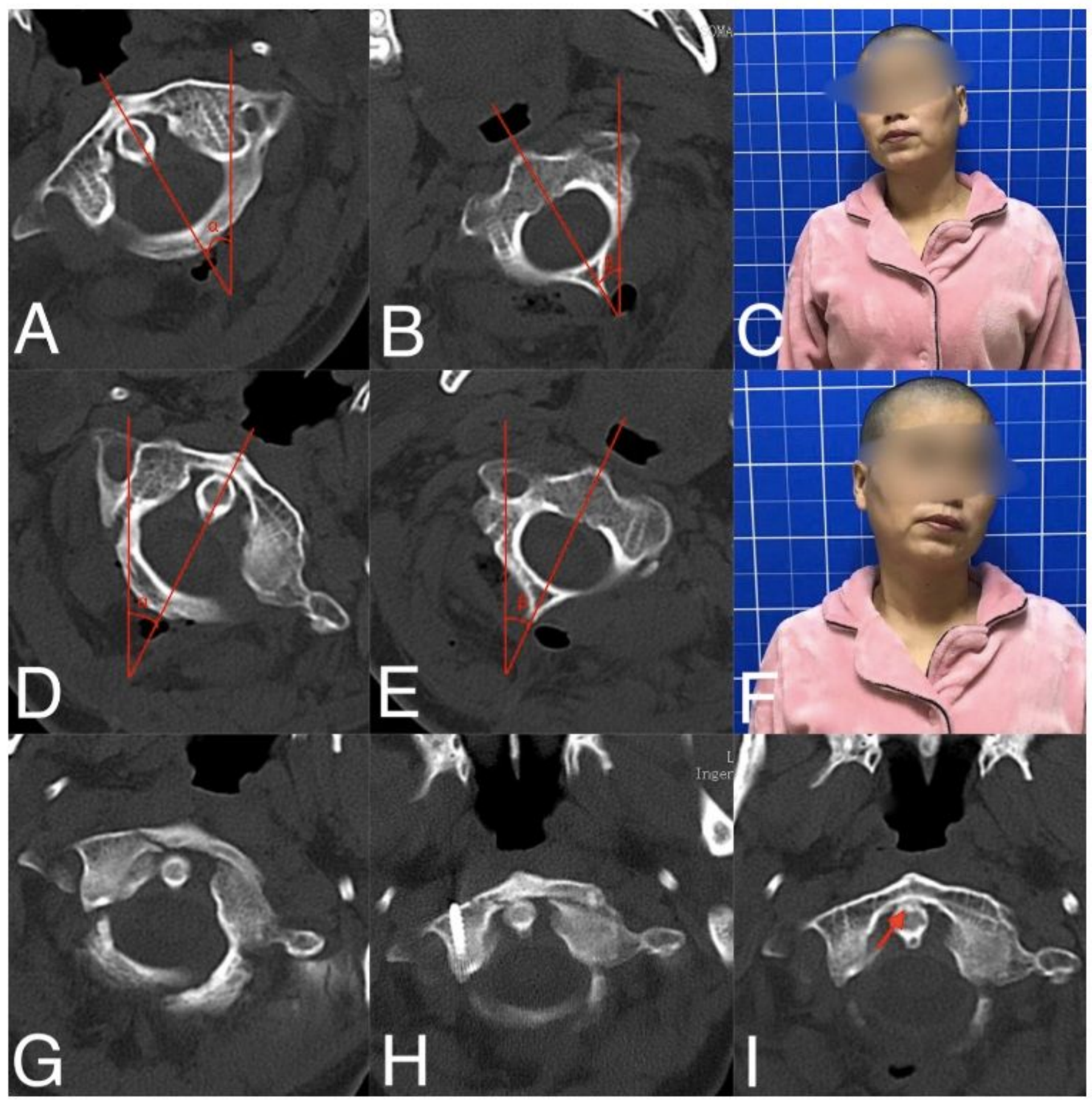

\section{Figure 2}

A showed maximum angle of $\mathrm{C} 1$ on the right side; $\mathrm{B}$ showed maximum angle of $\mathrm{C} 2$ on the right side. $\mathrm{D}$ showed maximum angle of $\mathrm{C} 1$ on the left side; $\mathrm{E}$ showed maximum angle of $\mathrm{C} 2$ on the left side. $\mathrm{G}$ showed $\mathrm{C} 1$ burst fracture before the operation. $\mathrm{H}$ showed post-operative of $\mathrm{C} 1$ after 3 months. I showed the union of posterior border of $\mathrm{C} 1$ anterior arch and apex of $\mathrm{C} 2$ (Red arrow). 